\title{
The Performance Appraisal Research on Higher School Teachers' Working Behavior
}

\author{
Xiaobai Lv \\ Management Department \\ Wuhan University of Science and Technology, WUST \\ Wuhan, China
}

\author{
Yifei $\mathrm{Yu}$ \\ Management Department \\ Wuhan University of Science and Technology, WUST \\ Wuhan, China
}

\begin{abstract}
Nowadays, for the prevalent higher school teachers' performance appraisal, using result-oriented appraisal metrics and methods has produced a series of problems. The author suggests that performance appraisal should focus on the process of teaching and education at the same time. We need to attach importance to the working result so as to realize the goal of stabilizing and enhancing the quality of teaching. Therefore, in this study, the author developed the measurement scales depend on the behavior-oriented method by analyzing teaching process in order to appraise higher school teacher's behavior performance.
\end{abstract}

Keywords-higher school teacher; working behavior; performance appraisal

\section{INTRODUCTION}

In 2012, a file named "Several Opinions on improving the quality of higher education comprehensively raised by the Ministry of Education (Ministry of Higher Education [2012] No.4)"advised improving teacher's professional skill and teaching ability by exploring the scientific appraisal methods of teaching ability. We realized that the quality of education is determined by the teacher, and a scientific appraisal method is an important way to enhance the quality of education.

Teacher in colleges has three basic functions, they are teaching, scientific research and providing social services. Currently, there are about 2500 colleges in China, and more than $70 \%$ of them are teaching universities (or colleges), and less than $5 \%$ of them are researching universities. And teaching is always the main responsibility in teaching universities and researching universities. For the documents we can consult right now, The widely used performance appraisal methods for higher school teacher are result-oriented methods, and the content of it includes finished class hours for a period of time (usually for one year), the quantity of guiding graduation thesis, the quantity of published academic papers, the honor achieved, the social services undertook and other working results easy to quantitative. The performance appraisal results are related to the assessment of teacher's title, the teacher's employment, the salary distribution and other benefit.

The concept of performance includes twofold content in the area of human resource management, they are affirmed working results and working behavior. The performance not only can be the reflection of working results or working behavior, but also can be the comprehensive reflection of working results and behavior. Although the result-oriented performance appraisal system is easy to design, to use, to understand and to arouse the working initiative of college teacher, but it is only fit for improving teacher's working output in the short term. As a Chinese saying goes, It only takes ten years to cultivate a tree, but a hundred years to bring up a child. To bring up a child is a training process which contains a series of teaching behavior, and the results of this process are lagged behind and concealed. Teaching is a primary responsibility of higher school teacher. Thus, only use resultoriented metrics and methods such as finished class hours to appraise the performance of teacher are not enough, It is not coincided with the responsibility of teaching.

\section{THE PERFORMANCE APPRAISAL OVERVIEW OF COLLEGE TEACHERS IN AMERICAN AND IN CHINA}

The western developed countries began to study appraisal system of teachers at the beginning of 20th century. After the $70 \mathrm{~s}$, there are many researchers do teacher's appraisal research, and many colleges have formed the teacher's appraisal system. After the 90s, the teacher's appraisal research developed more quickly, and then appeared many teacher's appraisal models and methods.

Before the 90s, American schools used rewards and punishment to appraise teacher. It usually appraises the finished teaching tasks and the support level to college activities of college teacher. In the mid 90s, The United States put forward a concept of development appraisal. It combined improving teaching quality with enhancing teacher's professionalization, and the purpose of the appraisal is to improve teacher's initiative, to enhance teacher's responsibility and to promote the communication.

There are two primary methods to appraise teacher in American. The first method is a value-added appraisal method based on students' progress. It appraises teacher's teaching effect according to the student's academic progress. The second method is a developmental appraisal method based on teacher's behavior. Its purpose is to better teacher's behavior and improve teacher's teaching level. It includes teaching process, interpersonal relationship, professional responsibility and so on.

There are three primary characteristics for American teacher's performance appraisal. Firstly, the categories of appraisal are varied, the standard of appraisal is different, the procedure of appraisal is conforming to the standard. Secondly, 
the content of appraisal is rich. It usually contains three aspects, they are teaching, scientific research and social services. And in many universities of arts and science and community colleges, teaching (quality) is the only standard to appraise teacher. Thirdly, the performance appraiser is varied.

The performance appraisal research was started in the 1960s in China, which later than western developed countries about 60 years. In the beginning, we only did performance appraisal on primary school teacher and middle school teacher. After China joined the IEA in May of 1984, we gradually did performance appraisal academic research. In the 21th century, many researchers did research on the existing literature or depend on their own experience or depend on studying cases of schools or design the performance appraisal system based on KPI and BSC. Researchers also used AHP and Fuzzy to select varied performance appraiser to do the research.

At present, college manager and academic has done a lot of research on performance appraisal system, and we have been applied some methods to college management practice. However, there are little research on methods of appraising key factors which effect teaching quality, such as teacher's quality, working attitude, working behavior and so on. and this caused imperfect of performance appraisal system.

\section{EXISTING OUTSTANDING PROBLEMS AND REASONS OF CURRENT PERFORMANCE APPRAISAL IN HIGHER SCHOOL}

There are many undeniable advantages of results-oriented performance appraisal methods, and it still has the value of existence at present, but it shows many problems in performance appraisal practice of higher school, here we'll talk about two outstanding problems.

At first, the performance appraisal focus on working results and overlooks working behavior, and this causes the deviation of work orientation. Due to the widespread adoption of resultsoriented performance appraisal metrics and methods in higher school, the teacher focus on work which can reach performance indicators in order to achieve the requirements of performance indicators. At the same time, they are not keen about other work, they are impatience with working process, they are not restrained themselves, they are anxious to achieve quick success and get instant benefit which help with speculating.

Secondly, Pursuing quantitative appraisal result has weakened the effect of performance feedback. As the quantitative performance appraisal result has characteristics of simple and clear, manager generally accepts that it can reflect the manager's performance accurately. As the teacher in higher school can totally understand the meaning of performance appraisal result, the task of performance feedback is only to let the teacher know performance appraisal result. However, if the teacher doesn't know which aspect has problems or how to solve existing problems, the performance feedback will not achieve the purpose of work improvement. At this point, the performance appraisal is no longer an effective measure to help the teacher achieve professional development, it has became a tool which puts pressure on the teacher, and it makes the teacher feel misunderstanding and antipathy.
The reasons of forming above problems are complicated, after studying, the author finds out two primary reasons. One is the shortage of professional ability in higher school's human resource management, the other is the neglect of higher school teacher's teaching characteristics.

There are many masters and PHD in higher school management team, but there is also a rotational system arrangement in the management team, so the professional degree of the teacher who do human resource management is not high, and the professional experience of the teacher is not enough, and these phenomena cause the shortage of human resource management ability. Lack of management ability makes manager can't analyze the teacher's work professionally, thus it has effect on choosing suitable management methods to solve the teacher's performance.

Teaching is a procedural and repetitive working process, and the results of this process are lagged behind and concealed. In the teaching process, the teacher needs passion and patience to attract students to learn knowledge and skills; the teacher needs teach directly through demonstration; the teacher needs to turn complex theories into easy understanding words, then the students can understand; the teacher needs to find out problems during teaching at all times and solve problems in time. In the teaching process, students are heavily influenced by teacher's behavior and value as well as learned knowledge. Thus, only using results-oriented performance appraisal metrics and methods to appraise teaching work is obviously unsuitable. To do appraisal on teacher's behavior is a part of teacher's performance appraisal. It will not only can help with reducing a series of problems raised by paying much attention to working results, but also will lead the teacher to work for improving teaching quality comprehensively as its behavior-oriented role, at the same time, it will help for recognizing and improving the teacher himself.

The author think that it is necessary to add teacher's working behavior in current performance appraisal system, it can form an integrated performance appraisal system. The system can balance teaching quantity with teaching quality and appraise teacher's performance comprehensively and objectively. Therefore, after two years study, the author developed a performance appraisal scale used for appraising higher school teacher's behavior. After learning a large amount of literature, there is no similar research right now. Therefore, the following performance appraisal scale for teacher's working behavior is initiative.

\section{THE PERFORMANCE APPRAISAL SCALE FOR TEACHER'S WORKING BEHAVIOR}

When the work can't get instant effect and definite results, using working behavior to measure the teacher's performance is a feasible way, and it can reflect work characteristics properly. In many companies which provide services, the behavior-oriented performance appraisal methods are widely used because services consist of a series of working behavior. The higher school is not the company, but its characteristic of providing services is similar to the company, especially for the teaching process, it is the process of providing intelligent 
services to student, so in higher school, it can also use behavior-oriented performance appraisal methods.

Using behavior-oriented performance appraisal methods to appraise teacher's performance need to do work analysis to teacher's position systematically at first, we need to analyze job responsibility and job qualification, we need to understand the teaching process, and we need to find a relationship between teacher's behavior and teaching quality. Then the author chooses a behavior-oriented performance appraisal method and develops an appraisal scale for practice.

\section{A. Teaching Process}

Teaching process consists of several primary parts, they are preparation before class, teaching on class, coaching and correcting homework after class. Preparation before class is to make preparation for lectures, it includes familiarity with teaching content, writing teaching program, making PPT and preparing for reference; teaching on class is to teach student, it is the key part of education; Coaching and correcting homework after class is to exam the effect of teaching, it includes correcting student's homework and answering questions.

\section{B. Performance Metrics and Working Behavior Group}

The research uses Pareto Principle to determine appraisal metrics. The research uses Delphi Method and an analyzing tool called fishbone diagram to make sure three appraisal dimension and eight appraisal metrics. The eight appraisal metrics are teaching ability, communicating ability, interpersonal relationship, working initiative and responsibility, cooperation, support to teaching management, teaching research and specialty construction. These form a system of working behavior appraisal metrics in table I . After analyzing job responsibility and job qualification of higher school teacher, we use methods of interview, case study, experience sum-up to collect information. Then the author develops a working behavior group which consists of 44 teaching behaviors.

TABLE I. WORKING BEHAVIOR APPRAISAL METRICS SYSTEM

\begin{tabular}{|c|c|c|}
\hline Dimension & metrics & Metrics’ Meaning \\
\hline \multirow{3}{*}{$\begin{array}{l}\text { Basic } \\
\text { Working } \\
\text { Ability }\end{array}$} & $\begin{array}{l}\text { Teaching } \\
\text { Ability }\end{array}$ & $\begin{array}{l}\text { Behavior during class's preparation and } \\
\text { teaching process; Answer questions; } \\
\text { Correct homework and so on }\end{array}$ \\
\hline & $\begin{array}{l}\text { Communicati } \\
\text { ng Ability }\end{array}$ & $\begin{array}{c}\text { When teaching has problems, the teacher } \\
\text { solves them by himself or by cooperating } \\
\text { with others. }\end{array}$ \\
\hline & $\begin{array}{l}\text { Interpersonal } \\
\text { Relationship }\end{array}$ & $\begin{array}{l}\text { The relationship between the teacher and } \\
\text { students, The relationship between the } \\
\text { teacher and colleagues, The relationship } \\
\text { between the teacher and leaders }\end{array}$ \\
\hline \multirow{3}{*}{$\begin{array}{l}\text { Working } \\
\text { Attitude }\end{array}$} & $\begin{array}{l}\text { working } \\
\text { initiative and } \\
\text { responsibility }\end{array}$ & $\begin{array}{l}\text { Working attitude represented; } \\
\text { demonstration effect on student }\end{array}$ \\
\hline & cooperation & Cooperating with others when working \\
\hline & $\begin{array}{l}\text { support to } \\
\text { teaching } \\
\text { management }\end{array}$ & $\begin{array}{l}\text { Participate in department meetings and } \\
\text { activities; Obeyed the leaders' } \\
\text { management }\end{array}$ \\
\hline \multirow{2}{*}{$\begin{array}{l}\text { Research } \\
\text { Ability }\end{array}$} & $\begin{array}{l}\text { teaching } \\
\text { research }\end{array}$ & $\begin{array}{l}\text { Improve teaching methods; Apply for and } \\
\text { participate in teaching research issue }\end{array}$ \\
\hline & $\begin{array}{l}\text { specialty } \\
\text { construction }\end{array}$ & $\begin{array}{l}\text { Guidance for young teachers, Support to } \\
\text { professional teaching team and so on }\end{array}$ \\
\hline
\end{tabular}

\section{Appraisal Methods}

There are several behavior-oriented performance appraisal methods, such as behaviorally anchored rating scale method, behaviorally contrasted scale method, behavioral observation scale, forced-choice scales and so on. Each method has its advantages and disadvantages, In theory, each method is able to appraiser teacher's behavior. However, in practice, we need to consider several factors such as independence, procedure and variation of working environment.

The procedural level of teacher's work in higher school is lower than workers in assembly line, but the teacher's working process has obvious procedural characteristic. Thus, the scale method which uses work standard to appraise is suitable for the teacher in higher school. The behaviorally anchored rating scale method, behavioral observation scale and forced-choice scales are methods suitable for appraising the teacher. Moreover, Teacher's work in higher school is independent, so behavioral observation scale and forced-choice scales is more suitable than behaviorally anchored rating scale method to appraise teacher's behavior. At last, the working environment of the teacher in high school is stable, it will not change at least for one semester. As a result, highly structured method such as forced-choice scales is suitable for higher school teacher.

Forced-choice scales originated in the United States, it is an unfamiliar method for researchers and managers in China. Forced-choice scales usually consists of 10-20 groups behavior, each group includes 2 positive behaviors and 2 negative behaviors. When using this scale, performance appraiser need to choose one behavior which most conforms to the person appraised and one behavior which most not conforms to the person appraised, and marking $\sqrt{ }$ on the most conformed behavior, marking $\times$ on the most not conformed behavior.

\section{Appraisal Scale}

After analyzing literature, the author develops performance appraisal scale for higher school teacher depend on the forcedchoice scales. This appraisal scale includes 11 groups of behavior, there are 44 items which cover 8 performance metrics in it. Here we represent it in Table II.

\section{E. The Test of Appraisal Scale}

In 2012, the author used "performance appraisal scale for teacher's working behavior" to appraise 60 teachers' performance in their teaching work. Then we can test the scale's validity and reliability. Table III is the performance appraisal tally sheet.

After data collection, we totally get 54 valid samples, they are integrated data of 54 teachers' working behavior appraisal. Each sample includes three performance appraiser, they are the leader of college or department, colleagues and the teacher himself. In order to count easily, we use simple average method to deal with the data of each performance appraiser for each sample. We collect about 1300 data, and here we only publish the study result. 
TABLE II. FULL-TIME TEACHER'S COMPREHENSIVE PERFORMANCE APPRAISAL SCALE

Full-time teacher's comprehensive performance appraisal scale Teacher appraised Department Time

Appraisal Description: Please choose one behavior which most conforms to the person appraised and amrking $\sqrt{ }$ on it, then choose one behavior which most not conforms to the person appraised and marking $\times$ on it.

1、Publishing papers on professional magazine

2、The teacher is good at dealing with interpersonal relationship.

3、 When meeting problems, the teacher rarely communicates with others to solve them.

4、 The teacher refuses to do work unrelated with teaching

1、The teacher likes to communicate with students and answer their questions

2、The teacher likes to discuss and improve teaching methods

3、Take no count of training and experiment

4、The teacher does not like spending time communicating with other

teachers about courses or helping young teachers.

1、Pay more attention to preparation of teaching work and its related work

2、Many students like the teacher.

3、 The teacher does not like to take part in research or school's meeting.

4、 The teacher does not correct student's homework or corrects it carelessly

1、Be willing to undertake the temporary task of college or department

2、Participate in the key course of specialty construction actively

3、 The teacher always accept work arranged by college leaders or department leaders negatively

4、 Not good at dealing with interpersonal relationship.

1、 Participate in the research of college or department actively

2. Give an initiative guidance to students on the second class activity.

3、The teacher likes to exaggerate the teaching efficiency

4、 The teacher's working style is dilatory.

1、 Participate in college teaching competition actively

2、The teacher cares about the student psychological status and living problems actively

3、The teacher does not like to undertake teaching task he/she never teaches.

4、 The teacher never interacts with students in class

1、The teacher usually uses positive examples or information to guide students.

2、 The teacher usually discusses teaching problems with other teachers actively

3、The teacher makes little effort in cooperation with school's management

4、The teacher usually has inappropriate comments in class

1、 The teacher joins in the construction of teaching team actively

2、The teacher cares for students employment

3、 Students is not satisfied with teacher's teaching.

4、 The teacher does not like to cooperate with others

1、The teacher usually likes to help others.

2、The teacher often gives constructive ideas to college.

3、The teacher does not like to accept appropriate suggestions from others

4、The teacher is satisfied with existing teaching situation, and he/she does not focus on knowledge update.

1、Be willing to share teaching experience and mistakes with other teachers

2、The teacher obeys the leader of college or department

3. The teacher does not like to attend other activities in college on additional time

4、 The teacher often cares about his own personal gain or loss

1、 Participate in the construction of training place or practice place

2、The teacher keeps on improving himself and pays attention to be

students model

3、The teacher often complains to his colleagues

4、 The teacher does not care about the public welfare activities.
TABLE III. TALLY SHEET

\begin{tabular}{|c|c|c|}
\hline Behavior Category & Appraisal & Score \\
\hline \multirow{2}{*}{ Positive Behavior } & $\sqrt{ }$ & 2 \\
\cline { 2 - 3 } & $\times$ & 0 \\
\hline \multirow{2}{*}{ Negative Behavior } & $\times$ & 1 \\
\cline { 2 - 3 } & $\sqrt{ }$ & -1 \\
\hline
\end{tabular}

At first we do reliability analysis (internal consistency analysis). We see the 44 behaviors as 44 variables. The result is that the Crobach's Alpha is 0.814. In the social science exploratory study, we usually think that Cronbach's Alpha needs to reach to 0.6 at least, otherwise the internal consistency is not enough. When the Cronbach's Alpha reach to 0.8, we believe that the internal consistency is really great. The result means the 44 variables (behaviors) of the teacher appraised get consistent score, it also means the result is reliable, internal consistent and stabilized.

Secondly, we do the validity analysis. The paper uses a widely used method in the field of psychology and medical called factor analysis to test the validity. Practically, we use the exploratory factor analysis and a software named SPSS13.0 to do it. After analysing, we find out the value of KMO is 0.589 , and in the Bartlett's test of sphericity, the Approx. Chi-Square is 207.280(df. is 28), the sig.(000) is less than 0.05, it means the correlation coefficient matrix is not a unit matrix. So the original variables are fit for factor analysis.

Thirdly, we do the factor analysis. The result shows that there are three factors, and the three factors totally explained $76.117 \%$ of original variables' total variance. In total, the information of original variables lost a little, the three factors explained most information of original variables, And after factor rotation, the cumulative variance ratio hasn't changed, it means factor rotation didn't affect the communalities of original variables, but the factor rotation reallocated the original variables' variance explained by each factor, and the factor rotation changed the variance contribution of each factor and it is easier to explain the factor. Table IV is the Rotated Factor Matrix.

TABLE IV. ROTATED FACTOR MATRIX

\begin{tabular}{|l|c|c|c|}
\hline \multirow{2}{*}{ Variable } & \multicolumn{2}{c|}{ Factor } \\
\cline { 2 - 4 } & 1 & 2 & 3 \\
\hline Cooperation & 0.756 & & \\
\hline Support to teaching management & 0.879 & & \\
\hline Working initiative and responsibility & 0.775 & & \\
\hline Teaching Research & & 0.87 & \\
\hline Specialty construction & & 0.864 & \\
\hline Interpersonal Relationship & & & 0.6 \\
\hline Communication Ability & & & 0.809 \\
\hline Teaching Ability & & & 0.881 \\
\hline
\end{tabular}


In Table IV, for the first factor, the rotated level of Cooperation, Support to teaching management and Working initiative and responsibility is higher than other variables. So the first factor mainly explains these three variables, we call it "Working Attitude". For the second factor, the rotated level of Teaching Research and Specialty construction is higher than other variables. So the second factor mainly explains these two variables, we call it "Research Ability". For the third factor, the rotated level of Interpersonal Relationship, Communication Ability and Teaching Ability is higher than other variables. So the third factor mainly explains these three variables, we call it "Basic Working Ability". Table V is the interpretation of each factor.

TABLE V. FACTOR INTERPRETATION

\begin{tabular}{|c|c|c|}
\hline Factor & Interpretation & Variables \\
\hline \multirow{3}{*}{1} & \multirow{3}{*}{ Working Attitude } & Cooperation \\
\hline & & Support to teaching management \\
\hline & & $\begin{array}{lll}\text { Working initiative } & \text { and } \\
\text { responsibility }\end{array}$ \\
\hline \multirow{2}{*}{2} & \multirow{2}{*}{ Research Ability } & Teaching Research \\
\hline & & Specialty construction \\
\hline \multirow{3}{*}{3} & \multirow{3}{*}{ Basic working Ability } & Interpersonal Relationship \\
\hline & & Communication Ability \\
\hline & & Teaching Ability \\
\hline
\end{tabular}

Through reliability analysis and validity analysis, the author finds out that the "performance appraisal scale for teacher's working behavior" is reliable and valid, it can completely used for appraising performance of higher school teacher's behavior.

Through the practical application of the scale in a university, we find out that the "performance appraisal scale for teacher's working behavior" is convenient to do performance feedback. After appraisal, we only need to find out the positive behavior which get the highest score and the negative behavior which get the lowest score. Then the manager can clearly make the performance feedback to the teacher. At the same time, through appraising himself and others, the teacher can clearly know the encouraged behavior and opposed behavior so that he can directly improve himself. Here we talk little about performance feedback because our point is to introduce the "performance appraisal scale for teacher's working behavior".

Above all, appraising higher school teacher's working behavior has enriched the decision-making basis of human resource management, it will change the teacher's attitude of being anxious to achieve quick success and get instant benefit, and it will help the teacher pay more attention to teaching process as well as focus on finished class hours. At last, we can reach the goal of improving teaching quality. However, there are many problems in the "performance appraisal scale for teacher's working behavior". So it is not easy to appraise the performance of higher school teacher's behavior, it need a long period of time to insistent study and continuous summary, Then we can get better research results.

\section{REFERENCES}

[1] Lv xiaobai,Wu youjun. "Performance Appraisal and Management". Beijing: Peking University Press,2013.

[2] Yan Yuping. A Comparative Study on Performance Appraisal for the teacher in America and in China. East China Normal University,2008, pp.29-30,40..

[3] Tian Aili. Development Performance Appraisal System depend on the teacher's behavior in America. Studies In Foreign Education,2003,30(4, pp. $15-18$

[4] Huang Weide, Niu kaiyun. A Comparative Study on Higher School Performance Appraisal System in America and in China. Journal of East China University of Science and Technology(Social Science Edition),2011,(6), pp.38-45..

[5] Gary P. Latham, Kenneth N. Wexley, Xiao mingzheng etc. translated. Increasing Productivity through Performance Appraisal(2nd Edition). Beijing: China Renmin University Press Co.LT, 2002. 